\title{
Root canal disinfection comparing conventional irrigation vs photon-induced photoacoustic streaming (PIPS) using a buffered $0.5 \%$ sodium hypochlorite solution
}

David E. Jaramillo ${ }^{1,2^{*}}$, Enrique Aguilar ${ }^{3}$, Ana Arias $^{4}$, Ronald Ordinola-Zapata ${ }^{5}$, Raydolfo M. Aprecio ${ }^{6}$ and Jose L. Ibarrola ${ }^{7}$

\begin{abstract}
Background: The purpose of this study was to assess the antimicrobial effect of a buffered $0.5 \%$ sodium hypochlorite solution activated by photon-induced photoacoustic streaming compared to conventional irrigation.

Methods: The canals on 48 single canal lower bicuspids were cleaned and shaped using rotary instrumentation. All roots were autoclaved for $20 \mathrm{~min}$. Thirty-six of the roots were placed in glass flasks with blood heart infusion media and Enterococcus faecalis (ATCC 4082) for 4 weeks. The remaining 12 roots were placed in a sterile environment and served as negative controls. The contaminated roots were irrigated by conventional means using a buffered $0.5 \%$ sodium hypochlorite solution with or without photon-induced photoacoustic streaming (PIPS) activation ( $n=12$ each group). The remaining 12 roots did not receive any treatment and served as positive controls. The apical $3 \mathrm{~mm}$ of each tooth was sectioned and pulverized. The pulverized samples were collected and placed in Eppendorf micro-centrifuge tubes with sterile phosphate-buffered saline. Thirty MicroLiters of the collected samples was then placed in the blood heart infusion media and incubated for $24 \mathrm{~h}$ at $37^{\circ} \mathrm{C}$. Colony forming units (CFU) were compared with Wilcoxon signed ranked test. Mann-Whitney $U$ test was used to assess PIPS effectiveness in comparison with conventional irrigation.
\end{abstract}

Results: Both regimens reduced significantly the number of $C F U$; however, reduction was significantly higher for the PIPS group $(p=0.002)$.

Conclusion: Buffered $0.5 \%$ sodium hypochlorite delivered by conventional method was effective in removing $E$. faecalis from contaminated root canals; however, activation of a buffered $0.5 \%$ sodium hypochlorite solution by PIPS significantly increased its antimicrobial capacity.

\section{Background}

The principal etiology in pulpal and periapical disease is the presence of bacteria in the root canal system (Happasalo et al. 2003). Anatomically complex root canal systems that contain lateral canal ramifications, isthmuses, cul-de-sacs, and other irregularities can impede the elimination of debris and bacteria from the root canal system (Wu et al. 2006). In

\footnotetext{
* Correspondence: David.E.Jaramillo@uth.tmc.edu

${ }^{1}$ Department of Endodontics, Loma Linda University, Loma Linda, CA, USA

2Department of Endodontics, UTHSC, Houston, TX, USA

Full list of author information is available at the end of the article
}

addition, bacteria can penetrate into dentinal tubules and persist after the completion of the endodontic therapy resulting in refractory infections years later (Vieira et al. 2012). Irrigation is the only way to impact those areas of the root canal system that cannot be cleaned by mechanical instrumentation (Happasalo et al. 2010).

The effectiveness and biocompatibility of irrigating solutions is dependent on a multiplicity of factors such as microorganism susceptibility, penetration of the solution to the infected site, concentration of the solution being used, and the toxicity to host cells (Mohammadi 2008). 
Sodium hypochlorite has long been considered the primary irrigating solution during endodontic procedures. It is an effective antimicrobial agent, and to date, it is the only solution capable of digesting organic tissue in the canal (Baumgartner and Cuenin 1992; Naenni et al. 2004). The antimicrobial and tissue-digesting capabilities of sodium hypochlorite are owed to chemical reactions that result in an alteration of bacterial cell metabolism as well as lipid and fatty acid degradation of cell membranes. Some of the interactions described are a saponification reaction, an amino acid neutralization reaction, and a chloramination reaction (Estrela et al. 2002).

A saponification reaction follows degradation of fatty acids in the cell membrane resulting in the formation of fatty acid salts (soap) and glycerol. Interactions between sodium hypochlorite and cell amino acids generate an exit of hydroxyl ions that in turn lower the $\mathrm{pH}$ of the solution which results in the release of hypochlorus acid which when in contact with organic tissue acts as a solvent-releasing chlorine which is a strong oxidant that inhibits bacterial enzymes by irreversibly oxidizing sulfhydryl groups of essential bacterial enzymes. Chlorines also combine with protein amino groups resulting in the formation of chloramines that interfere with bacterial cell metabolism (Estrela et al. 2002).

In addition, phagocytic cells through the production of hydrogen peroxide which together with $\mathrm{Cl}$ - ions serve as substrates for the enzyme myeloperoxidase can generate the release of hypochlorous acid $(\mathrm{HOCl})$ which plays a vital role in the ability of phagocytic cells to kill bacteria. Even at low concentrations, hypochlorous acid has shown the ability for a rapid and selective inhibition of bacterial growth and cell division (Mckenna and Davies 1988). To maintain a more stable solution of hypochlorus acid and to potentially increase its antibacterial activity, the $\mathrm{pH}$ of a sodium hypochlorite solution can be lowered by adding a buffering solution. Therefore, altering the $\mathrm{pH}$ of a lower strength sodium hypochlorite solution may increase its antibacterial properties by facilitating the release of hypochlorus acid.

Conversely, these same chemical properties can degrade and interfere with the metabolism of host cells. Prolonged inadvertent contact with host cells can lead to damage of the host cells resulting in pain and a chemically induced inflammatory reaction (Zhu et al. 2013). Therefore, obtaining a balance between safety and effectiveness is important. The amount of damage to host cells has been shown to be directly proportional to the concentration of the sodium hypochlorite solution; thus, the higher the concentration of sodium hypochlorite, the higher the potential for host cell damage. Sodium hypochlorite has been used in different concentrations ranging from 0.5 to $5.25 \%$ with varying degrees of effectiveness. Different studies have shown that reducing the concentration of sodium hypochlorite will reduce the cytotoxicity of the irrigant but will decrease its bactericidal and tissue dissolution capabilities (Zhang et al. 2003; Radcliffe et al. 2004).

At the same time, different irrigation activation methods such as vibrating tips, sonic, and ultrasonic irrigation have been recommended to enhance the efficiency of traditional syringe/needle delivery (Happasalo et al. 2010; Happasalo et al. 2014; Niu et al. 2014). In 2009, a photon-induced irrigation system with a modified stripped radial firing erbium/ YAG laser tip that produces a photoacoustic shockwave that can facilitate irrigants to stream into canal irregularities such as lateral canals, anastomoses, and dentinal tubules was introduced (Malterud 2013; DiVito et al. 2011; Lloyd et al. 2014). This technology is known as photon-induced photoacoustic streaming (PIPS) and has the potential to enhance the cleaning and disinfection of inaccessible areas of the root canal system (Jaramillo 2015).

This study aims to evaluate the effectiveness of a buffered $0.5 \%$ sodium hypochlorite solution in eradicating Enterococcus faecalis from the root canal system and to see if activation by PIPS further increases its antimicrobial properties. Since the cytotoxicity of sodium hypochlorite is directly proportional to the concentration of the solution, the authors felt it was necessary to investigate if a lower concentration of sodium hypochlorite would be effective in eradicating bacteria from the root canal system. Furthermore, it is of interest to see if activation of buffered $0.5 \%$ sodium hypochlorite solution by PIPS would further enhance its antimicrobial properties. It would be beneficial to use an irrigating solution that is effective in eliminating bacteria from the root canal system while reducing its cytotoxic effect.

\section{Methods}

Forty-eight single canal lower bicuspid roots were selected for this study. The clinical crown was sectioned on each tooth to obtain a standardized length of $16 \mathrm{~mm}$. Apical patency was established with a \#10 k file (Dentsply-Maillefer, Switzerland), and the canals were then mechanically prepared using ProTaper Universal rotary system (Dentsply, Tulsa Dental, Johnson City, TN) to an F3 file size. Root canals were irrigated with a $1 \%$ sodium hypochlorite solution during shaping. A final irrigation with a $17 \%$ EDTA solution followed for $5 \mathrm{~min}$ to ensure the dentinal tubules were accessible. The prepared teeth were then autoclaved at a temperature of $121{ }^{\circ} \mathrm{C}$ at 20 PSI for $20 \mathrm{~min}$. Thirty six roots were placed in 250-ml Erlenmeyer flasks (Nova Tech International, Kingwood, TX) filled with brain heart infusion (BHI) media and inoculated with E. faecalis (ATCC4082). The samples were kept in the BHI media for 4 weeks. The BHI media were replenished every 3 days while incubated (Shel Lab, Vernon Hills, IL) at $37{ }^{\circ} \mathrm{C}$. The remaining 12 roots were maintained sterile and served as negative controls. After 4 weeks, the root canals were flooded with phosphate-buffered saline (PBS) (Mediatech Inc, Manassas 
VA), and dentinal debris was produced using a \#30 size Hedström file (Dentsply-Maillefer, Switzerland). The samples were then taken with paper points and placed in Eppendorf tubes containing PBS. The samples were mixed using a Vortex Genie 2 mixer (Scientific Industries, Bohemia NY) for $15 \mathrm{~s}$. Afterwards, $30 \mu \mathrm{l}$ of the solution was collected from each tube and cultured on petri dishes containing BHI agar. The petri dishes were then placed in an incubator at $37{ }^{\circ} \mathrm{C}(\mathrm{S} 1)$. Colony forming units (CFU) were determined after $24 \mathrm{~h}$ of incubation. Bacterial growths were confirmed by gram staining.

The 36 contaminated roots were randomly assigned to either of the three groups (12 samples each): the positive control group which received no treatment; the conventional delivery irrigation method group (CDM). The samples were irrigated with $2 \mathrm{ml}$ of a buffered $0.5 \%$ sodium hypochlorite solution prepared using the methodology described by Zehnder (Zehnder et al. 2002) by a conventional delivery method utilizing an irrigation syringe (BectonDickinson, Franklin Lakes, NJ) and a side-vented needle (Patterson, Endodontic Irrigation Needles, St. Paul, MN); and the PIPS group. The samples were irrigated with the same buffered $0.5 \%$ sodium hypochlorite solution but activated with three cycles using PIPS Er:YAG laser $2940 \mathrm{~nm}$ for $30 \mathrm{~s}$. After the second cycle, a 30-s rest period followed before completion of the final cycle of a laseractivated irrigation. The sodium hypochlorite solution was replenished before each new cycle. PIPS activation always occurred in the presence of constant sodium hypochlorite irrigation. A constant reservoir of sodium hypochlorite was ensured by coronal isolation with CoreRestore2 photo-cured resin (Kerr Dental, Orange, CA).

All root samples from both experimental groups and the control groups were immersed for $5 \mathrm{~min}$ in 1-ml Eppendorf tubes (Eppendorf North America, Hauppauge, $\mathrm{NY)}$ containing a $5 \%$ sodium thiosulfate solution in order to inactivate the sodium hypochlorite solution. Once the sodium hypochlorite was inactivated, the roots were sectioned using an Isomet 1000 precision saw (Buehler, Lake Bluff, IL). The apical $3 \mathrm{~mm}$ of each root were collected and placed in 50-ml test tubes containing liquid nitrogen (Praxair, Danbury, CT). The frozen samples were then triturated using sterile and individually assigned pestle and mortars. The triturated samples were collected and placed in Eppendorf tubes filled with PBS. The contents were blended using a vortex Genie 2 mixer, $30 \mu \mathrm{l}$, and the resulting solution was taken and placed in petri dishes containing BHI agar. The cultures were then placed in an incubator at a temperature of $37^{\circ} \mathrm{C}$ for $24 \mathrm{~h}$ (S2). Bacterial colonies were gram-stained and quantified by direct observation using the same methodology described by Chavez De Paz (Chavez de Paz et al. 2003).

Before and after CFU were compared for each irrigation regimen. The data contradicts the assumption of normal distribution and therefore was analyzed with related-samples Wilcoxon signed ranked test. MannWhitney $U$ test was used to assess PIPS effectiveness in eliminating E. faecalis from the root canal system utilizing a buffered $0.5 \%$ sodium hypochlorite solution in comparison with conventional delivery irrigation by a needle/syringe method using the same irrigant.

\section{Results}

Mean values and standard deviations of before and after CFU for each irrigation regimen are shown in Table 1. Both irrigation regimens reduced significantly the number of CFU ( $p=0.002$ and $p=0.0001$, respectively, for needle/ syringe delivery method and PIPS); however, reduction of CFU was significantly higher for PIPS group than for the needle syringe delivery group. Irrigation with a buffered $0.5 \% \mathrm{NaOCl}$ activated with PIPS was significantly more effective in eliminating $E$. faecalis from the root canal system than irrigation with buffered $0.5 \% \mathrm{NaOCl}$ delivered by needle/syringe method $(p=0.002)$. The negative control group did not yield any measurable CFU units.

\section{Discussion}

This in vitro study was designed to assess the effectiveness of a $\mathrm{pH}$-altered solution of $0.5 \%$ of sodium hypochlorite in combination with PIPS in canals contaminated with $E$. faecalis as a final irrigation protocol.

One of the principal objectives of endodontic therapy is to eliminate bacteria from the root canal system. This can be accomplished though mechanical instrumentation and chemical irrigation. The use of irrigating solutions is important since there are areas of the root canal system that are inaccessible to instrumentation. Sodium hypochlorite has long been considered the primary irrigating solution during endodontic procedures. However, sodium hypochlorite can have an adverse response on host cells. Spencer et al. (2007) gave a detailed description of the adverse effects of injecting sodium hypochlorite into the periapical tissues. At the same time, it has been shown that although lower concentrations of sodium hypochlorite are less cytotoxic to host tissues, lowering its concentration will result in a reduction of its antimicrobial effectiveness and tissue digestion capabilities (Zhang et al. 2003; Fachin et al. 1994). Radcliffe et al. (2004) found E. faecalis to be the most resistant strain

Table 1 Mean values and standard deviations of before and after CFU for each irrigation regimen

\begin{tabular}{lll}
\hline & \multicolumn{2}{l}{ Colony forming units } \\
\cline { 2 - 3 } Irrigation regimen & Before & After \\
\hline Conventional delivery & $4.83 \pm 0.39$ & $1.42 \pm 1^{*}$ \\
PIPS & $4.92 \pm 0.29$ & $0.25 \pm 0.45^{*}$ \\
\hline
\end{tabular}

*Statistical significant differences between groups 
to sodium hypochlorite and found that lower concentrations of the solution required longer contact times with the microorganisms; a $0.5 \%$ solution of $\mathrm{NaOCl}$ required 30 min of contact to totally eradicate E. faecalis whereas a concentration of $5.25 \% \mathrm{NaOCl}$ only required 2 min of contact time. Gomes et al. (2001) evaluated the antimicrobial effect of $0.5,1,2.5,4$, and $5.25 \%$ sodium hypochlorite solutions in the elimination of E. faecalis; their results showed $5.25 \%$ sodium hypochlorite to be the most effective antibacterial agent. In contrast, D'Arcangelo et al. (1999) analyzed the effectiveness of $0.5,1,3 \%$, and $5 \%$ $\mathrm{NaOCl}$ on facultative and strict anaerobic bacteria and showed that all concentrations had an antibacterial effect on all species tested.

Different irrigation activation methods such as vibrating tips, sonic, and ultrasonic irrigation have been recommended to compensate for the limitations of a traditional syringe/needle delivery method (Happasalo et al. 2010; Mohammadi 2008; Baumgartner and Cuenin 1992). Among them, the use of lasers has been recommended as aids in the disinfection of root canal systems (Himel et al. 2006). However, several studies have demonstrated that its use may not result in an optimal bacterial reduction (Noetzel et al. 2009). A great number of variables such as the delivery technique utilized, the time of application within the canal, the presence of an aqueous solution that would affect the absorption of the laser beam, and the power settings utilized might have influenced previously reported results.

Temperature rise of tooth structure and surrounding tissues is an important consideration when utilizing laser energy in the cleaning and disinfection of the root canal system. Irradiation intensity and use of a water coolant have a significant impact on the amount of heat generated during laser utilization (Kimura et al. 2002). PIPS uses a sub-ablative photoacoustic technique that allows the penetration of the irrigating solution into inaccessible areas of the root canal system, killing bacteria not by a thermal event but rather by antimicrobial irrigants that are activated by the photomechanical effects of the PIPS-tapered and stripped laser tip (Jaramillo et al. 2012). Previous studies have shown that PIPS in combination with 5.25 and $6 \%$ sodium hypochlorite is an effective means of eliminating resistant bacteria such as E. faecalis from the root canal system (Jaramillo et al. 2012; Olivi et al. 2014).

Another critical issue during laser-driven activation is the risk of apical extrusion of irrigants. It is important to confine the irrigating solution to the confines of the root canal system. Peters et al. (2012) used a mixture of a radiopaque contrast medium and $\mathrm{NaOCl}$ solution in 300 canals in 181 patients and activated the solution with an erbium laser for $60 \mathrm{~s}$ in teeth with one or two canals and $120 \mathrm{~s}$ on teeth with three or four canals. The study showed that laser-activated irrigation does not produce apical extrusion of the irrigant, to the point that contrast media could not be detected radiographically in any of the samples.

\section{Conclusions}

A buffered $0.5 \%$ sodium hypochlorite solution delivered by the needle syringe method was effective in eradicating $E$. faecalis from the root canal system. However, activation of buffered $0.5 \%$ sodium hypochlorite by PIPS significantly increased its antimicrobial effectiveness. It is important to use the least cytotoxic irrigating solutions during endodontic therapy without compromising its antimicrobial efficacy. In addition, the use of PIPS allows the irrigating solution to reach otherwise inaccessible areas of the root canal system, thereby increasing the effectiveness of such irrigants.

\section{Authors' contributions}

DEJ carried out the experiment design, implemented sample preparation and conducted the microbiological sampling. EA carried out the clinical preparation of root samples. AA conducted the statistical analysis of results. $\mathrm{ROZ}$ conducted the study design and literature review. RMA prepared the microbiological samples. JLI drafted the manuscript and conducted the literature search and review. All authors read and approved the final manuscript.

\section{Competing interests \\ The authors declare that they have no competing interests.}

\section{Author details}

${ }^{1}$ Department of Endodontics, Loma Linda University, Loma Linda, CA, USA. ${ }^{2}$ Department of Endodontics, UTHSC, Houston, TX, USA. ${ }^{3}$ Department of Endodontics, Universidad Autonoma de Baja California, Tijuana, BCN, Mexico. ${ }^{4}$ Department of Conservative Dentistry, Complutense University of Madrid, Madrid, Spain. ${ }^{5}$ Department of Endodontics, Bauru School of Dentistry, University of Sao Paulo, Bauru, SP, Brazil. ${ }^{6}$ Center for Dental Research, School of Dentistry, Loma Linda University, Loma Linda, CA, USA. ${ }^{7}$ Creighton University, School of Dentistry, Omaha, NE, USA.

Received: 11 June 2016 Accepted: 24 June 2016

Published online: 05 August 2016

\section{References}

Happasalo M, Udnaes T, Endal U. Persistent, recurrent, and acquired infection of the root canal system post-treatment. Endod Top. 2003;6:29-56.

Wu MK, Dummer PM, Wesselink PR. Consequences of and strategies to deal with residual post-treatment root canal infection. Int Endod J. 2006;39:346-56.

Vieira AR, Siqueira Jr JE, Ricucci D, Lopes WSP. Dentinal tubule infection as the cause of recurrent disease and late endodontic treatment failure: a case report. J Endod. 2012;38:250-4.

Happasalo M, Shen Y, Qian W, Gao Y. Irrigation in endodontics. Dent Clin N Am. 2010;54:291-312.

Mohammadi Z. Sodium hypochlorite in endodontics an update review. Int Den J. 2008;58:329-41.

Baumgartner JC, Cuenin PR. Efficiency of several concentrations of sodium hypochlorite for root canal irrigation. J Endod. 1992;18:605-12.

Naenni N, Thoma K, Zehnder M. Soft tissue dissolution capacity of currently used and potential endodontic irrigants. J Endod. 2004;30:113-7.

Estrela C, Estrela CR, Barbin EL, Spano JC, Marchesan MA, Pecora JD. Mechanism of action of sodium hypochlorite. Braz Dent J. 2002;13:113-7.

Mckenna SM, Davies KJA. The inhibition of bacterial growth by hypochlorous acid possible role in the bacterial activity of phagocytes. Biochem J. 1988; 254:685-92.

Zhu WC, Gyamfi J, Niu LN, Schoeffel GJ, Kiu SY, Santarcangelo F, et al. Anatomy of sodium hypochlorite accidents involving facial ecchymosis a review. J Dent. 2013:41:935-48.

Zhang W, Torabinejad M, Li Y. Evaluation of cytotoxicity of MTAD using the MTTtetrazolium method. J Endod. 2003;29:654-7. 
Radcliffe CE, Potouridou L, Qureshi R, Habahbeh N, Qualtrough A, Worthington H, et al. Antimicrobial activity of varying concentrations of sodium hypochlorite on the endodontic microorganisms Actinomyces israelii, A. naeslundii, Candida albicans and Enterococcus faecalis. Int Endod J. 2004;37:438-46.

Happasalo M, Wang Z, Shen Y, Curtis A, Patel P, Khakpour M. Tissue dissolution by a novel multisonic ultracleaning system and sodium hypochlorite. J Endod. 2014;40:1178-81.

Niu LN, Luo XJ, Li GH, Bortoluzzi EA, Mao J, Chen JH, et al. Effects of different sonic activation protocols on debridement efficacy in teeth with single rooted canals. J Dent. 2014;42:1001-9.

Malterud M. Minimally invasive biomimetic endodontics: the future is here. Gen Dent. 2013;61:8-10.

DiVito EE, Colonna MP, Olivi G. The photoacoustic efficacy of an ER:Yag laser with radial and stripped tips on root canal dentin walls: An SEM evaluation. J Laser Dent. 2011:19:156-61.

Lloyd A, Uhles JP, Clement DJ, Garcia GF. Elimination of intracanal tissue and debris through a novel laser-activated system assessed using high resolution micro-computed tomography: a pilot study. J Endod. 2014;40:584-7.

Jaramillo DE. Irrigation of the root canal system by laser activation (LAI): PIPS photon-induced photoacoustic streaming. In: Basrani B, editor. Endodontic irrigation. Switzerland: Springer international publishing; 2015. p. 227-36.

Zehnder M, Kosicki D, Luder H, Sener B, Waltimo T. Tissue-dissolving capacity and antibacterial effect of buffered and unbuffered hypochlorite solutions. Oral Surg Oral Med Oral Pathol. 2002;94:756-62.

Chavez de Paz LE, Dahlen G, Molander A, Möller A, Bergenholtz G. Bacteria recovered from teeth with apical periodontitis after antimicrobial endodontic treatment. Int Endod J. 2003;36:500-8.

Noetzel J, Nonhoff J, Bitter K, Wagner J, Neumann K, Kielbassa AM. Efficacy of calcium hydroxide, Er:YAG laser or gaseous ozone against Enterococcus faecalis in root canals. Am J Dent. 2009;22:14-8.

Jaramillo DE, Aprecio RM, Angelov N, DiVito E, McClammy TV. Efficacy of photon induced photoacoustic streaming (PIPS) on root canals infected with Enterococcus faecalis: a pilot study. Endod Prac. 2012;5:28-32.

Olivi G, DiVito E, Peters O, Kaitsas V, Angiero F, Signore A, et al. Disinfection efficacy of photon-induced photoacoustic streaming on root canals infected with Enterococcus faecalis: an ex vivo study. J Am Dent A. 2014;145:843-8.

Spencer HR, Ike V, Brennan A. Review: the use of sodium hypochlorite in endodontics-potential complications and their management. Brit Dent J. 2007;202:555-9.

Peters HH, Mooduto L. Radiographic examination of apical extrusion of root canal irrigants during cavitation induced by Er,Cr:YSGG laser irradiation: an in vivo study. Clin Oral Invest 2012; DOI 10.1007/s00784-012-0910-2

Gomes BP, Ferraz CC, Vianna ME. In vitro antimicrobial activity of several concentrations of sodium hypochlorite and chlorhexidine gluconate in the elimination of Enterococcus faecalis. Int Endod J. 2001;34:424-8.

D'Arcangelo C, Varvara G, De Fazio P. An evaluation of the action of different root canal irrigants on facultative aerobic-anaerobic, obligate anaerobic, and microaerophilic bacteria. J Endod. 1999:25:351-3.

Fachin EVF, Hahn L, Palmini ALF. Revisão e enfoque clínico sobre o uso do hipoclorito de sódio em endodontia. Rev Bras Endod. 1994;51:14-8.

Himel VT, McSpadden JT, Goodis HE. Instruments materials and devices. In: Cohen S, Hargreaves KM, editors. Pathways of the pulp. Saint Louis: Mosby: 2006. p. 279-80.

Kimura Y, Yonaga K, Yokoyama K, Kinoshita J, Ogata Y, Matsumoto K. Root surface temperature increase during Er:YAG laser irradiation of root canals. $J$ Endodon. 2002;28:76

\section{Submit your manuscript to a SpringerOpen ${ }^{\circ}$ journal and benefit from:}

- Convenient online submission

- Rigorous peer review

- Immediate publication on acceptance

- Open access: articles freely available online

- High visibility within the field

Retaining the copyright to your article

Submit your next manuscript at $\gg$ springeropen.com 